\title{
The frailty syndrome in institutionalized elderly persons
}

\author{
Marina Tadini Fluetti' \\ Jack Roberto Silva Fhon ${ }^{2}$ \\ Ana Paula de Oliveira ${ }^{3}$ \\ Larissa Martins Ortega Chiquito? \\ Sueli Marques ${ }^{4}$
}

\section{Abstract}

Objective: to analyze the relationship between the level of frailty and sociodemographic and health characteristics among elderly residents of a long-term care facility (LTCF) in Ribeirão Preto, São Paulo, Brazil. Method: this descriptive and cross-sectional study included 56 elderly persons living in a LTCF. Data were collected from April to June 2016. A questionnaire addressing sociodemographic and health profiles was used together with the Mini-Mental State Examination, the Tilburg Frailty Indicator, the Barthel Index, and the Geriatric Depression Scale (GDS-15). Descriptive statistics were applied. The normality of the continuous variables was tested using the Shapiro-Wilk test. Spearman's correlation was used for the continuous variables with frailty as the dependent variable. Result: Most elderly individuals were female (57.1\%); the average age was 77.77 ; and $35.7 \%$ were widowed. In terms of health, $55.4 \%$ presented cognitive deficit; $62.5 \%$ had depression symptoms; $75.0 \%$ were considered frail; $42.9 \%$ had suffered falls in the last 12 months; and the individuals scored an average of 68.30 in the Barthel Index. A positive correlation between the frailty score and the GDS-15 $(r=0.538 ; p=0.00)$ was observed, while a negative correlation was found between frailty and the Barthel Index $(\mathrm{r}=-0.302 ; p=0.02)$. Conclusion: increased frailty among institutionalized elderly persons is correlated with the presence of depressive symptoms and inferior performance of basic activities of daily living. The results of the present study can support the planning of care provided to elderly individuals living in LTCFs and encourage broader assessments of these individuals.

\footnotetext{
Universidade de São Paulo, Escola de Enfermagem de Ribeirão Preto, Curso de Graduação Bacharelado em Enfermagem. Ribeirão Preto, SP, Brasil.

2 Universidade de São Paulo, Escola de Enfermagem de Ribeirão Preto, Programa de Pós-graduação em Enfermagem Fundamental. Ribeirão Preto, SP, Brasil.

3 Instituição Sociedade Espirita Cinco de Setembro, Setor de Enfermagem. Ribeirão Preto, SP, Brasil.

4 Universidade de São Paulo, Escola de Enfermagem de Ribeirão Preto, Departamento de Enfermagem Geral e Especializada. Ribeirão Preto, SP, Brasil
}

Keywords: Frail Elderly. Geriatric Nursing. Homes for the Aged.

Correspondence

Sueli Marques

E-mail:smarques@eerp.usp.br 


\section{INTRODUCTION}

Brazil is undergoing a process of increasing population aging. It is estimated that by 2020 people aged 60 and over will represent $13.8 \%$ of the total population, rising to $33.7 \%$ in $2060^{1}$.

The process of human aging is multifactorial and progressive in all its dimensions: biological, psychological, socioeconomic, cultural and spiritual ${ }^{2}$. This results in a loss of functional reserve, which makes the individual more susceptible to chronic diseases, which in turn can contribute to a reduction in functionality and the emergence of the frailty syndrome ${ }^{3}$. Frailty is an important indicator of the health condition of elderly persons, and research has therefore been carried out to elaborate a concept of frailty which can be used in health service practices. Due to its multidimensional nature, however, the challenge of establishing a definition has yet to be overcome ${ }^{4}$.

Frailty is a state of vulnerability with poor resolution of homeostasis after a stressor event, increasing the risk of adverse outcomes such as muscle weakness, bone fragility, malnutrition, risk of falls, vulnerability to trauma and infections, as well as unstable blood pressure and decreased functional capacity ${ }^{5}$. For this study, frailty is understood as a dynamic state that affects individuals who suffer losses in one or more domains of human functioning (physical, psychological and social), caused by the influence of a series of variables, and which increases the risk of adverse events ${ }^{6}$.

The elderly population has distinct characteristics in relation to other age groups and their health assessment requires a wide and multidimensional investigation, encompassing functional, cognitive, psychic, nutritional and social evaluations, performed by a multi-professional team, to guarantee the best possible evaluation and treatment for elderly persons and thus prioritize their autonomy and independence in the environment in which they live?
Deficits in functional, cognitive and psychic abilities are the major cause of loss of independence, causing the elderly to require more care when performing activities of daily living. The difficulties encountered by the family or the impossibility of finding a caregiver means Long-Term Care Facilities for the Elderly (LTCFs) are sought to meet these requirements. Institutionalization is not common in Brazil, with only $0.8 \%$ of the elderly population living in LTCFs, but it is believed that there will be an increase in these numbers in the near future ${ }^{10}$.

The description of the factors associated with frail elderly persons, especially in LTCFs, is rare in Brazilian literature. The presence of frailty can compromise the quality of life of the elderly population. In view of the above, the research question proposed is: what is the relationship between frailty and the sociodemographic and health characteristics of elderly persons living in a longterm care facility?

Based on this question, the objectives of the present study were to identify the cognitive ability, degree of independence for basic activities of daily living, presence of depressive symptoms and level of frailty of elderly persons residing in an LTCF in the city of Ribeirão Preto, São Paulo, and to analyze the relationship between the level of frailty and sociodemographic and health characteristics.

\section{METHOD}

A quantitative, descriptive and cross-sectional study was carried out in a LTCF in the city of Ribeirão Preto, São Paulo, Brazil. The study population was the elderly persons living in the LTCF between April and June 2016, who met the inclusion criteria: be 60 years of age or older, of both genders and be able to communicate verbally, and the exclusion criteria: have a medical diagnosis of dementia.

Thus, the study population was composed of 56 elderly people, as set out in Figure 1. 


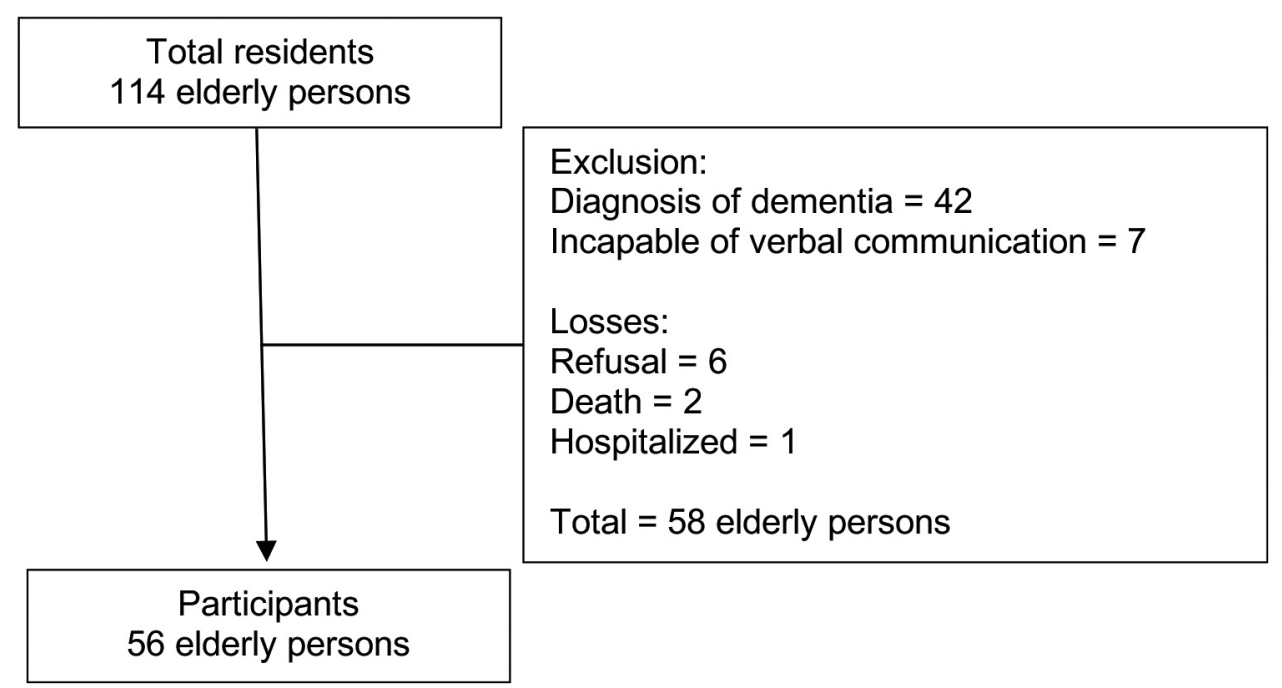

Figure 1. Flowchart of study population, Ribeirão Preto, São Paulo, 2016.

Data collection was carried out in the aforementioned period through an interview conducted by one of the researchers, using the following instruments:

a) sociodemographic and health questionnaire, containing information regarding gender, age, schooling, marital status, monthly income; health status - medical diagnoses, number of medications used (data collected from medical records) and number of falls in the last 12 months;

b) Mini-Mental State Exam, developed to evaluate cognitive function ${ }^{11}$ and validated for Brazil ${ }^{12}$. This consists of seven categories, temporal orientation, spatial orientation, word registration, attention and calculation, recall (memory of recall), language and visual constructive ability, with variation from zero to 30 points. Due to the influence of schooling on performance in this instrument, the following cut-off scores were applied in the present study, 13 points for illiterates; 18 for schooling from one to four years; 26 for five to eight years and 30 for nine years or more ${ }^{12}$;

c) Tilburg Frailty Indicator (TFI) created with the purpose of measuring the level of frailty of the elderly for the use of health professionals ${ }^{13}$. It has been adapted transculturally and validated for Brazil ${ }^{14}$, and the reliability of the internal consistency of the
Brazilian version was considered satisfactory, with a Cronbach alpha of 0.78. It contains 15 questions distributed in three domains, physical (eight questions) related to health, weight loss, difficulty walking, maintaining balance, weakness, fatigue, vision and hearing; psychological (four questions) that assess cognition, the presence of depressive symptoms, anxiety and coping, and social (three questions) regarding social relations and support. Scores vary from zero to 15 points, with the highest score indicating a higher level of frailty, although the authors determined a cutoff point of $\geq 5$ to indicate frailty in the individual ${ }^{13}$,

d) Barthel Index, to measure the performance of basic activities of daily living (BADL) $)^{15}$, translated and validated for Brazil, with a sensitivity of $92.7 \%$ and a specificity of $65.2 \%{ }^{16}$. This evaluates performance for feeding, bathing, dressing, personal hygiene, bowel and bladder elimination, toilet use, chair-bed transfer, walking, and the ability to go up and down stairs. The score ranges from zero to 100 points, with higher scores indicating greater independence ${ }^{16}$.

e) Geriatric Depression Scale (GDS-15) validated for Brazil with test-retest ( $r h o=0.86, p<0.001$ ), a Kappa coefficient of 0.64 and good internal consistency, with a Cronbach's alpha score of 0.8117. 
The GDS-15 is composed of 15 items and evaluates satisfaction with life, interruption of activities, anger or irritation, mood, isolation, energy, joy and problems related to memory. It has scores from 0 to 15 , where zero represents absence of depressive symptoms and fifteen indicates a greater presence of these symptoms. The cut-off point $\geq 5$ was used to categorize the elderly with depressive symptoms ${ }^{17}$.

The interviews were carried out at the LTCF, where the elderly persons were approached by the researcher, who identified herself, explained the study, and discussed the free and informed consent form. After signing of the same by the elderly, they went to a location (bedroom or other room) to guarantee privacy and avoid possible interruptions and noise. The mean duration of the interviews was 29 minutes.

For the qualitative variables (nominal and ordinal), simple frequency calculations were performed, as well as contingency tables and prevalence ratios. For the quantitative variables measures of central tendency (mean and median) and variability were used (standard deviation, shown in the text as \pm , and amplitude). For the numerical variables, normality was tested by means of the Shapiro-Wilk test. It was verified that the number of diseases and falls data of the Barthel scale did not follow normality, and so the use of non-parametric tests was necessary. The Spearman correlation was used for the numerical variables, with frailty as the dependent variable.

The study was authorized by the board of directors of the LTCF and approved by the Research Ethics Committee of the Ribeirão Preto Nursing School of the Universidade de São Paulo, CAE 51034615.0.0000.5393. Authorizations were requested for the use of all scales used in this study.

\section{RESULTS}

A total of 56 elderly people living in the LTCF participated in the study, with a predominance of females (57.1\%) and a mean age of 77.77 years $( \pm 9.27)$, the majority $(46.4 \%)$ of whom were 80 years or older. A total of $35.7 \%$ of the elderly persons were widowers. The majority $(53.6 \%)$ had between one and four years of schooling and the mean number of years of study was 4.70 ( \pm 3.58$)$. Of the elderly surveyed, $82.1 \%$ reported being retired with an average monthly income of $\mathrm{R} \$ 1,136.96( \pm \mathrm{R} \$ 1,134.22)$ (Table 1).

The mean time of institutionalization of the elderly persons was 36.34 months $( \pm 46.56)$ and the main reason for residing in the LTCF was the need for care $(60.7 \%)$. The majority $(75.0 \%)$ reported that they shared their bedroom with another person(s). It was verified that $89.2 \%$ of the elderly received visits from family or friends and $33.9 \%$ reported leaving the LTCF to visit family members.

In the evaluation of health, $55.4 \%$ of the elderly had cognitive deficits, $62.5 \%$ had depressive symptoms and $75.0 \%$ were classified as frail. A total of $42.8 \%$ of the elderly persons reported having fallen in the last 12 months, and the mean number of falls was 2.04 ( \pm 1.96$)$. The mean number of diseases was $3.68( \pm 1.85)$, and $44.6 \%$ had three to four diseases. The median number of medications of continuous use was $8.89( \pm 3.87)$ and $42.9 \%$ took between six and ten medications. Regarding the performance of basic activities of daily living, the mean score on the Barthel scale was 68.30 ( \pm 2.78$)$ (Table 2).

There was a positive correlation between the Frailty Indicator score and GDS-15 $(\mathrm{r}=0.538, p=0.00)$ and a negative correlation between frailty and the performance of BADL ( $\mathrm{r}=-0.302 ; p=0.02)$ (Table 3$)$. 
Table 1. Distribution of elderly persons living in a Long Term Care Facility according to sociodemographic variables. Ribeirão Preto, São Paulo, 2016.

\begin{tabular}{|c|c|c|c|c|c|}
\hline Variables & $\mathrm{n}(\%)$ & Mean & Standard Deviation & Minimum & Maximum \\
\hline \multicolumn{6}{|l|}{ Gender } \\
\hline Female & $32(57.1)$ & & & & \\
\hline Male & $24(42.9)$ & & & & \\
\hline Age (in years) & & 77.77 & 9.27 & 61 & 93 \\
\hline $61-69$ & $14(25.0)$ & & & & \\
\hline $70-79$ & $16(28.6)$ & & & & \\
\hline 80 or more & $26(46.4)$ & & & & \\
\hline \multicolumn{6}{|l|}{ Marital Status } \\
\hline Single & $18(32.1)$ & & & & \\
\hline Married & $6(10.7)$ & & & & \\
\hline Widowed & $20(35.7)$ & & & & \\
\hline Separated/divorced & $12(21.4)$ & & & & \\
\hline Schooling (years) & & 4.7 & 3.58 & 0 & 13 \\
\hline Illiterate & $9(16.1)$ & & & & \\
\hline $1-4$ & $30(53.6)$ & & & & \\
\hline $5-8$ & $6(10.7)$ & & & & \\
\hline $9-11$ & $6(10.7)$ & & & & \\
\hline 12 or more & $5(8.9)$ & & & & \\
\hline Income (in reais) & & 1136.96 & 1134.22 & 0 & 6000 \\
\hline Pension & $46(82.1)$ & & & & \\
\hline Pension and retirement payments & $5(8.9)$ & & & & \\
\hline None & $5(8.9)$ & & & & \\
\hline
\end{tabular}

Table created by authors

Table 2. Distribution of elderly persons living in a Long Term Care Facility according to health variables. Ribeirão Preto, São Paulo, 2016.

\begin{tabular}{|c|c|c|c|c|c|}
\hline Variables & $\mathrm{n}(\%)$ & Mean & Standard Deviation & Minimum & Maximum \\
\hline \multicolumn{6}{|l|}{ Cognitive state } \\
\hline Deficit & $31(55.4)$ & 16.52 & 6.04 & 6 & 28 \\
\hline Without deficit & $25(44.6)$ & 21.6 & 2.95 & 16 & 29 \\
\hline Depressive symptoms & & 5.82 & 3.16 & 0 & 13 \\
\hline With & $35(62.5)$ & & & & \\
\hline Without & $21(37.5)$ & & & & \\
\hline Frailty & & 6.64 & 2.78 & 2 & 13 \\
\hline Not frail & $14(25.0)$ & & & & \\
\hline Frail & $42(75.0)$ & & & & \\
\hline Falls in last 12 months & & 2.04 & 1.96 & 1 & 10 \\
\hline 1 & $13(23.2)$ & & & & \\
\hline $2-3$ & $9(16.1)$ & & & & \\
\hline$\geq 4$ & $2(3.6)$ & & & & \\
\hline None & $32(57.2)$ & & & & \\
\hline
\end{tabular}


Continuation of Table 2

\begin{tabular}{llllll}
\hline Variables & $\mathrm{n}(\%)$ & Mean & Standard Deviation & Minimum & Maximum \\
\hline Number of diseases & & 3.68 & 1.85 & 1 & 9 \\
$1-2$ & $15(26.8)$ & & & & \\
$3-4$ & $25(44.6)$ & & & 1 & 16 \\
5 & $16(28.6)$ & & & & \\
\hline Number of medications & & 8.89 & 3.87 & & \\
$1-5$ & $10(17.9)$ & & & & \\
$6-10$ & $24(42.9)$ & & & 15 & 100 \\
$\geq 11$ & $22(39.3)$ & & & & \\
Barthel Index & & 68.3 & 2.78 & & \\
\hline
\end{tabular}

Table created by authors

Table 3. Correlation coefficient between frailty scores and the sociodemographic and health variables of the elderly living in a Long Term Care Facility, Ribeirão Preto, São Paulo, 2016.

\begin{tabular}{lll}
\hline Variables & $\mathrm{r}$ & $p$-value \\
\hline Age & 0.08 & 0.55 \\
Education & 0.14 & 0.92 \\
Income & -0.78 & 0.6 \\
Time to live ILPI & -0.08 & 0.51 \\
Cognitive status & -0.23 & 0.08 \\
Number of diseases & -0.09 & 0.42 \\
Number of medicines & -0.01 & 0.9 \\
Number of falls & -0.03 & 0.88 \\
Performance of BADL & -0.3 & 0.02 \\
Depressive symptoms & 0.538 & $<0.001$ \\
\hline
\end{tabular}

Spearman Correlation; $p \leq 0.05$; Table created by authors

\section{DISCUSSION}

A predominance of women was found in the present study, a result which was also observed in other studies ${ }^{3,18}$ and which can be explained by the greater longevity of women. In Brazil, the life expectancy for men is 70.5 years and 77.7 for women ${ }^{1}$. The average age was 77.7 years, with the majority of respondents aged 80 years old or older. In a study conducted in Juiz de Fora, Minas Gerais, it was verified that $55.7 \%$ of the institutionalized elderly were 80 years old or older, with a mean of 80.3 years $^{18}$.

In terms of marital status, single and widowed institutionalized elderly persons have been found to be more prevalent, as was observed in this study. The absence of a partner and weak social and family support are factors that lead to the institutionalization of the elderly ${ }^{19}$.
The mean level of schooling was considered low. Generally, low levels of schooling are found in studies with elderly populations, as education was not a priority in the childhood of these individuals, especially for females ${ }^{20}$. There was a predominance of retirees, which corroborates with data from another study that indicates that the source of income of the elderly population is through pensions or retirement payments $(66.2 \%)$, from half to one minimum wage per month $(38.3 \%)^{1}$.

The mean time of institutionalization found in the present study is similar to that found in a study which identified an average of 37 months $^{21}$. The place where one lives is not just a physical space but is a refuge, a place for rest, protection and to store belongings. It also represents a space of expressions, stories and memories that relate to the life of its inhabitants ${ }^{22}$. The main reason for institutionalization was the 
need for care. Elderly persons living in LTCFs generally, despite having family members, opt to live in the institution due to the loneliness and illness caused by age, which leads them to require care and companionship ${ }^{23}$.

Regarding the health evaluation of the elderly persons studied, the majority had cognitive deficits, although no statistically significant correlation with frailty was found. In Poland, a study with 86 institutionalized elderly showed that $55.8 \%$ had severe cognitive impairment and $26.7 \%$ had moderate cognitive impairment ${ }^{24}$. It is known that frailty and cognitive deficit are directly related, since elderly people with cognitive deficits present greater loss of strength and muscle mass, fatigue, gait alteration and body composition, which lead to frailty ${ }^{25}$. In addition, the decline in cognitive status associated with the frailty syndrome increases the risk of mortality in the elderly ${ }^{5}$.

Another aspect evaluated in the participants was the presence of depressive symptoms, which revealed a predominance of elderly people with such symptoms. A study with 205 elderly people, using the GDS, found that $65.0 \%$ had depressive symptoms, with an average of 7.3 points $( \pm 3.37)^{26}$. Depression is a psychiatric syndrome characterized by behavioral changes, feelings of worthlessness, emotional distress and reduced quality of $\mathrm{life}^{27}$. Depression may be related to social and affective issues, as well as the perception of elderly persons about institutionalization in relation to factors such as isolation, lack of family members, reduced activities, lack of financial flexibility and the process of adaptation.

A high prevalence $(75.0 \%)$ of frail elderly persons, with a mean of 6.64 points, was found in the present study. In a literature review ${ }^{28}$, it was found that the prevalence of frailty in the community dwelling elderly persons was lower than that of elderly persons in hospitals or long-term institutions. In a study in the Netherlands ${ }^{13}$ of elderly residents in the community using the TFI, the prevalence of frailty was $47.0 \%$, while a Brazilian study of institutionalized elderly people found a rate of $52.0 \%$, with an average of 4.9 points $^{29}$. In a study with hospitalized elderly persons using the Edmonton Frail Scale ${ }^{30}, 95.2 \%$ were considered frail.
One possible explanation for this finding was the fact that institutionalized elderly persons are afflicted by health problems that make them more susceptible to the frailty syndrome ${ }^{28}$.

The prevalence of falls suffered in the last 12 months was $42.8 \%$, with an average of 2.04 . According to a study conducted in New Haven, Connecticut, USA, the probability of an elderly person being institutionalized after a hospital stay due to hip fracture or fall-related injuries is greater than after hospitalizations not associated with such events ${ }^{31}$. Another study carried out with 744 institutionalized individuals over 65 years of age indicated an average number of falls of 2.4 per person per year and concluded that elderly people living in LTCFs generally have more than one risk factor for falls, such as a higher prevalence of comorbidities, cognitive and functional deficits and polypharmacy $y^{32}$, leading to a decrease/loss of autonomy, functional capacity and the worsening of quality of $\mathrm{life}^{28}$.

The mean numbers of diagnosed diseases and medications in use observed in this study were higher than those found in another study ${ }^{18}$. It is known that institutionalized elderly individuals suffer greater health impairment than elderly residents who live in the community. Generally, elderly persons with a greater number of comorbidities make concomitant use of several medications, leading to poorer health conditions, which may lead to a decrease in functional performance and increase the vulnerability of the elderly ${ }^{19}$.

Decreased functionality can cause a loss of independence. The maintenance of self-care is fundamental to living well and, therefore, the search for knowledge and information about the maintenance of health, the regular practice of physical activity, the adoption of healthy habits and monitoring in health services are determinant factors for sustaining a desirable level of functioning, thereby delaying disability and providing benefits for the biopsychosocial health of the elderly ${ }^{33}$.

The present study identified a negative correlation between frailty and the performance of BADL, with a higher TFI score (greater frailty) associated with a lower Barthel Index score (greater dependence). Another study identified that the reduction of 
the capacity of the elderly to perform basic and instrumental activities of daily living was related to the presence of the frailty syndrome. Both are indicated as important markers of health for the elderly, and so professionals in this area must apply programs that minimize frailty and its consequences ${ }^{34}$.

A positive correlation between frailty and the presence of depressive symptoms was also observed, with a higher TFI score (greater frailty) associated with a higher GDS-15 score (greater presence of depressive symptoms). It should also be emphasized, however, that the psychological domain of the TFI also evaluates mood, which may have influenced this result.

Although the appearance of depressive symptoms may contribute to both functional impairment and frailty, becoming a risk factor for frailty syndrome, these symptoms can also be considered signs of the early manifestation of this syndrome, as the causes of the association between frailty and depression remain unknown ${ }^{35}$.

Due to the high prevalence of frailty and the severity of this syndrome, it is important to identify the factors associated with the condition in a broad sense, so that care for frail elderly persons can be planned by a multi-professional team, considering physical, psychological and social elements.

Regarding the limitations of this study, the results presented are specific to the population studied, and so generalizations should be viewed with caution to avoid misunderstandings. In addition, because it is a cross-sectional study, the causality of the frailty identified cannot be determined.

\section{REFERENCES}

1. Instituto Brasileiro de Geografia e Estatística. Síntese de indicadores sociais: uma análise das condições de vida da população brasileira 2014 [Internet]. Rio de Janeiro: IBGE; 2014 [acesso em 19 nov. 2016]. Disponível em: ftp://ftp.ibge.gov.br/Indicadores_Sociais/Sintese_de_ Indicadores_Sociais_2014/SIS_2014.Pdf

2. Willig MH, Lenardt MH, Caldas CP. Longevity according to life histories of the oldest-old. Rev Bras Enferm. 2015;68(4):697-704.

\section{CONCLUSION}

The results of the present study of institutionalized elderly persons revealed that the majority were women, most of whom were 80 years of age or older. There was also a predominance of elderly people with cognitive deficits and with depressive and frail symptoms. There was a correlation between increased frailty and the presence of depressive symptoms and reduced performance in basic activities of daily living.

It is known that frailty implies negative aspects for the quality of life of the elderly, leading to hospitalization, institutionalization and even death. Frail elderly persons should be considered a priority group in public health policies, with a focus on prevention, treatment and rehabilitation.

This syndrome encompasses biological, psychological, social and cognitive factors, and so the comprehensive evaluation of the elderly is necessary. This should be carried out by a multiprofessional team, through instruments that allow the evaluation of all these dimensions, with the purpose of supporting the planning of care for the elderly and the early identification of frailty, with the possibility of minimizing the consequences and harm caused by the condition.

It is therefore hoped that the results of the present study can support the planning of care for elderly residents of such institutions, in addition to encouraging broader assessments of these elderly people.

3. Linhares JC, Oliveira EN, Eloia SC, Freitas CASL, Shinkai H, Lira TQ. Condições sociais e de saúde de idosos acompanhados pela Atenção Primária de Sobral-CE. Rev RENE. 2011;12(Esp.):922-9.

4. Rockwood K. Frailty and its definition: a worthy challenge. J Am Geriatr Soc. 2005;53(6):1069-70.

5. Fried LP, Tangem CM, Walston J, Newman AB, Hirsch C, Gottdiener J, et al. Frailty in older adults: evidence for a phenotype. J Gerontol Ser A Biol Sci Med Sci. 2001;56(3):146-56. 
6. Gobbens RJJ, Van Assen MALM. Frailty and its prediction of disability and health care utilization: the added value of interviews and physical measures following a self-report questionnaire. Arch Gerontol Geriatr. 2012;55(2):369-79.

7. Torres SVS. A valorização da queixa do idoso no cuidado em vários contextos. Rev Kairós. 2015;18(Esp. 19):9-23.

8. Borges CL, Freitas MC, Guedes MVC, Silva MJ, Leite SFP. Prática clínica do enfermeiro no cuidado ao idoso fragilizado: estudo de reflexão. Rev Enferm UFPE online. 2016;10(Supl. 2):914-8.

9. Teixeira JS, Corrêa JC, Rafael CBS, Miranda VPN, Ferreira MEC. Envelhecimento e percepção corporal de idosos institucionalizados. Rev Bras Geriatr Gerontol. 2012;15(1):63-8.

10. Silva MV, Figueiredo MLF. Idosos institucionalizados: uma reflexão para o cuidado de longo prazo. Enferm Foco. 2012;3(1):22-4.

11. Folstein MF, Folstein SE, McHugh PR. Mini-mental state: a practical method for grading the cognitive state of patients for the clinician. J Psychiatr Res. 1975;12(3):189-98.

12. Bertolucci PH, Brucki SM, Campacci SR, Juliano Y. O Mini-Exame do Estado Mental em uma população geral: impacto da escolaridade. Arq Neuropsiquiatr. 1994;52(1):1-7.

13. Gobbens RJJ, Van Assen MA, Luijkx KG, WijnenSponselee MT, Schols JM. The Tilburg Frailty Indicator: psychometrics properties. J Am Med Dir Assoc. 2010;11(5):344-55.

14. Santiago LM, Luz LL, Gobbens RJJ. Adaptação transcultural do instrumento Tilburg Frailty Indicator (TFI) para a população brasileira. Cad Saúde Pública. 2012;28(9):1795-1801.

15. Mahoney FI, Barthel DW. Functional evaluation: the Barthel Index. Md State Med J. 1965;14:61-5.

16. Minosso JSM, Amendola F, Alvarenga MRM, Oliveira MAC. Validação, no Brasil, do Índice de Barthel em idosos atendidos em ambulatórios. Acta Paul Enferm. 2010;23(2):218-23.

17. Almeida OP, Almeida SA. Short versions of the Geriatric Depression Scale: a study of their validity for the diagnosis of a major depressive episode according to ICD-10 and DSM-IV. Int J Geriatr Psychiatry. 1999;14(10):858-65.

18. Fochat RC, Horsth RBO, Vianna CLC, Raposo NRB, Vieira RCPA, Chicourel EL. Perfil sociodemográfico de idosos frágeis institucionalizados em Juiz de Fora Minas Gerais. Rev APS. 2012;15(2):178-84.
19. Santiago LM, Luz LL, Silva JFS, Oliveira PH, Carmo $\mathrm{CN}$, Mattos IE. Condições sociodemográficas e de saúde de idosos institucionalizados em cidades do sudeste e centro-oeste do Brasil. Geriatr Gerontol Aging. 2016;10(2):86-92.

20. Alves-Silva JD, Scrosolini-Comin F, Santos MA. Idosos em instituições de longa permanência: desenvolvimento, condições de vida e saúde. Psicol Reflex Crit. 2013;6(4):820-30.

21. Lisboa CR, Chianca TCM. Perfil epidemiológico, clínico e de independência funcional de uma população idosa institucionalizada. Rev Bras Enferm. 2012;65(3):482-8.

22. Avelar MCM. O envelhecimento e a moradia: análise empírica em uma instituição de longa permanência e a perspectiva do residente idoso. Rev Kairos. 2010;13(8):61-77.

23. Vieira FP, Leston NIM, Ulguim MDFM, Silva JRS, Siqueira HCH. Caminhos que levam o idoso a conviver em instituições de longa permanência para idosos. Vittalle. 2012;24(1):47-52.

24. Matusik P, Tomaszewski K, Chmielowska K, Nowak J, Nowak W, Parnicka A, et al. Severe frailty and cognitive impairment are related to higher mortality in 12-month follow-up of nursing home residents. Arch Gerontol Geriatr. 2012;55(1):22-4.

25. Buchman AS, Bennett DA. Cognitive Frailty. J Nutr Health Aging. 2013;17(9):738-9.

26. Kowalska J, Rymaszewska J, Szczepanska-Gieracha J. Ocurrence of cognitive impairment and depressive symptoms among the elderly in a nursing home facility. Adv Clin Exp Med. 2003;22(1):111-7.

27. Batistone SST. Depressão. In: Guariento ME, Neri AL. Assistência ambulatorial ao idoso. Campinas: Alinea; 2010. p. 235-42.

28. Pinto Junior EP, Marques CG, Silva AVS, Guimarães MAP, Pedreira RBS, Silva MGC. Prevalência e fatores associados ao fenótipo da fragilidade em idosos brasileiros: uma revisão de literatura. Rev Kairós. 2015;18(3):353-66.

29. Santiago LM, Mattos IE. Prevalência e fatores associados à fragilidade em idosos institucionalizados das regiões Sudeste e Centro-Oeste do Brasil. Rev Bras Geriatr Gerontol. 2014;17(2):327-37.

30. StortiL B, Fabricio-Whebe CC, Kusumota L, Rodrigues RAP, Marques S. Fragilidade de idosos internados na clínica médica da unidade de emergência de um hospital geral terciário. Texto \& Contexto Enferm. 2013;22(2):452-9.HYPERLINK "https:// dx.doi.org/10.1590/S0104-07072013000200022" $\backslash \mathrm{h}$ HYPERLINK "https://dx.doi.org/10.1590/ S0104-07072013000200022" \h 
31. Hausdorff JM, Rios DA, Edelberg HK. Gait variability and fall risk in community-living older adults: a 1-year prospective study. Arch Phys Med Rehabil. 2001;82(8):1050-6.

32. Damián J, Pastor-Barriuso R, Valderrama-Gama E, Pedro-Cuesta J. Factors associated with falls among older adults living in institutions. BMC Geriatr. 2013;13(6):1-9.

Received: July 05, 2017

Reviewed: November 10, 2017

Accepted: December 26, 2017
33. Maciel MG. Atividade física e funcionalidade do idoso. Motriz. 2010;16(4):1024-32.

34. Fhon JRS, Diniz MA, Leonardo KC, Kusumota L, Rodrigues RAP. Síndrome de fragilidade relacionada à incapacidade funcional no idoso. Acta Paul Enferm. 2012;25(4):589-94.

35. Pegorari MS, Tavares DMS. Fatores associados à síndrome de fragilidade em idosos residentes em área urbana. Rev Latinoam Enferm. 2014;22(5):874-82. 